\title{
Effects of myoinhibitory peptides on food intake in the German cockroach
}

\section{RUTH AGUILAR ${ }^{1}$, JOSÉ L. MAESTRO* and XAVIER BELLÉS}

Department of Physiology and Molecular Biodiversity, Institut de Biologia Molecular de Barcelona (CSIC), Jordi Girona 18-26, 08034 Barcelona, Spain.

${ }^{1}$ Present address: Department of Molecular Microbiology and Immunology, Johns Hopkins Bloomberg School of Public Health, Baltimore, MD 21205, USA.

\begin{abstract}
Insect myoinhibitory peptides were discovered through their inhibitory activity on visceral muscle contraction. We tested the antimyotropic gut properties of three galanin-related myoinhibitory peptides (Mas-MIP II: GWQDLNSAW-NH ${ }_{2}$, Grb-ASTB1: GWQDLNGGW-NH 2 and Grb-AST-B3: AWRDLSGGW-NH $\mathrm{N}_{2}$ ) in adult females of the cockroach Blattella germanica (L.) (Dictyoptera, Blattellidae). The three peptides elicit a strong inhibitory effect on both foregut and hindgut contractions, with $\mathrm{ID}_{50}$ values in all the cases within the nanomolar range. In addition, the modulatory effects of these three peptides on food intake were studied on previously starved female cockroaches. Results show that Grb-AST-B3 is the most active peptide, inhibiting food intake by $60-80 \%$ at doses between 15 and $50 \mu \mathrm{g}$, followed by Grb-AST-B1 (45\% inhibition of food intake at $50 \mu \mathrm{g}$ dose), whereas Mas-MIP II is inactive even at the 50 $\mu \mathrm{g}$ dose. The differences between the three peptides could be due to a differential effect of their structure on activity or to a differential degradation. These results show that myomodulatory gut activity in vitro and antifeeding effects do not always correlate.
\end{abstract}

Short title: Antifeeding effect of myoinhibitory peptides

Key words. Blattella germanica, food intake regulation, German cockroach, myoinhibitory activity, myoinhibitory peptides.

*Corresponding author. Tel.: +34-93-4006135; fax: +34-93-2045904. E-mail address: jmgagr@ibmb.csic.es (J.L. Maestro). 


\section{Introduction}

Insect peptides belonging to the myoinhibitory peptide family are usually nonapeptides, characterised by a residue Trp at positions 2 and 9 and by an amidated Cterminus. The first member of this family was identified from extracts of brain-corpora cardiaca-corpora allata-suboesophageal ganglion from Locusta migratoria, and was called Lom-MIP (from MyoInhibitory Peptide), in accordance with its inhibitory activity on hindgut and oviduct contractions (Schoofs et al., 1991). Later, other peptides belonging to this family were identified in the Lepidoptera Manduca sexta (Mas-MIP-I to VI: Blackburn et al., 1995; 2001), Bombyx mori (Bom-PTSP=Mas-MIP-I: Hua et al., 1999), Lacanobia oleracea (Mas-MIP-VI: Audsley \& Weaver, 2003), the Orthoptera Gryllus bimaculatus (Grb-AST-B1 to 5: Lorenz et al., 1995; 1999), the Dictyoptera Periplaneta americana (Pea-MIP: Predel et al., 2001) and the Phasmida Carausius morosus (Cam-AST-B1 to 6: Lorenz et al., 2000). In addition, the cDNA of the preproprotein containing the five myoinhibitory peptides of the dipteran Drosophila melanogaster (Williamson et al., 2001), and a partial cDNA containing three previously described and a novel peptide of G. bimaculatus (Wang et al., 2004) have also been reported. Biological activities described for these peptides include the inhibition of visceral muscle contraction in locusts, moths and cockroaches (Schoofs et al., 1991; Blackburn et al., 1995; 2001; Predel et al., 2001), the inhibition of Juvenile Hormone (JH) production in crickets (Lorenz et al., 1995; 1999; 2000), the inhibition of ecdysteroidogenesis in moth prothoracic gland (Hua et al., 1999) and in cricket ovary (Lorenz et al., 1997), and the inhibition of adipokinetic hormone release in locusts (Vullings et al., 1999).

Anatomical localization of myoinhibitory peptides using immunocytochemical techniques has given further physiological support to most of the known biological activities. For example, myoinhibitory peptide-like immunoreactivity has been localized in several areas of the brain and in the corpora cardiaca-corpora allata complex of the cockroach P. americana (Predel et al., 2001), the locust L. migratoria (Schoofs et al., 1996) and the cricket G. bimaculatus (Witek et al., 1999). These locations fit well with the described activities of myoinhibitory peptides on adipokinetic hormone release in locusts, and on juvenile hormone production in crickets. In addition, immunoreactivity has been observed in neurons from the ventral nerve cord innervating the heart, oviduct and hindgut of locust (Schoofs et al., 1996), and the foregut and hindgut of the 
American cockroach (Predel et al., 2001), which is compatible with myotropic functions in these organs. The occurrence of immunoreactivity in different neurohemal organs suggests that the myoinhibitory peptides act as true hormones (Predel et al., 2001; Davis et al., 2003). Furthermore, in situ hybridization experiments in D. melanogaster larvae have shown myoinhibitory peptide expression in the central nervous system and in midgut endocrine cells (Williamson et al., 2001), which suggests that these peptides have a role on feeding and digestive processes.

The amino acid sequence of some myoinhibitory peptides shows a certain degree of similarity with the N-terminal sequence of vertebrate galanins (Table 1). Galanins are 29/30-residue neuropeptides found in the gastrointestinal tract and nervous system of vertebrates, predominantly in the hypothalamus. They are linked to a number of functions, including the stimulation of food intake (Crawley, 1999; Halford \& Blundell, 2000). In addition, galanins show myotropic action on the smooth musculature of mammal gastrointestinal tract, stimulating or inhibiting motility depending on the particular region or tissue (Ekblad et al., 1985; Rattan \& Tamura, 1998).

Blattella germanica (L.) is an anautogenous cockroach, which means that the adult female requires a proteinaceous meal before starting vitellogenesis and ovogenesis (Osorio et al., 1998). Thus, the female has a feeding cycle that almost parallels that of vitellogenesis. In the $B$. germanica colony studied here, food consumption in the adult female starts $24 \mathrm{~h}$ after the imaginal moult, peaks on day 4 and decreases steadily thereafter until day 7, when oviposition occurs (Osorio et al., 1998). As this pattern suggests that food intake is finely regulated, the regulatory mechanisms have been investigated, and the peptide perisulfakinin identified as a putative satiety factor (Maestro et al., 2001). In addition, a number of YXFGL-NH $\mathrm{N}_{2}$ allatostatins and leucomyosuppressin have been shown to inhibit food intake, an activity possibly based on the antimyotropic gut effects of these peptides (Aguilar et al., 2003, 2004).

The antimyotropic activity of myoinhibitory peptides on insect gut motility (Schoofs et al., 1991; Blackburn et al., 1995; 2001; Predel et al., 2001), their gene expression in midgut endocrine cells of D. melanogaster (Williamson et al., 2001) and their sequence similarity with the $\mathrm{N}$-terminal region of vertebrate galanins, suggest that the myoinhibitory peptides might be involved in the regulation of food intake in insects. It is to test this hypothesis that the activity of three galanin-related insect myoinhibitory 
peptides on foregut and hindgut motility, and on food intake in adult females of the German cockroach, B. germanica have been studied.

\section{Material and methods}

\section{Insect rearing}

Adult females of the German cockroach, B. germanica (L.), (Dictyoptera, Blattellidae) were obtained from a colony fed on dog chow and water and reared in the dark at $30 \pm 1^{\circ} \mathrm{C}$ and $60-70 \%$ relative humidity.

\section{Myotropic bioassay}

Peptides belonging to the myoinhibitory peptide family were tested on the foregut and hindgut from 3-day-old adult females of B. germanica maintained in a 500 $\mu 1$ standard organ bath, as described elsewhere (Maestro et al., 2001; Aguilar et al., 2003). A FSG-01 transducer (Experimetria Ltd, Budapest, Hungary) was used for isometric recording. The activity was calculated as the difference of the mean of the force produced by the tissue $1 \mathrm{~min}$ after and $1 \mathrm{~min}$ before treatment.

\section{Feeding bioassay}

The feeding bioassay was carried out as reported previously (Maestro et al., 2001). Freshly ecdysed adult females were starved for 48 h, injected with saline or with the corresponding myoinhibitory peptide, and provided with carrot ad libitum. The females had then access to food for $5 \mathrm{~h}$ (in which time carotenoids do not appear in the faeces), after which the whole gut was dissected out and extracted with methanol. Carotenoid concentration in the methanolic extracts was estimated by spectrophotometric measurement of the absorbance at $450 \mathrm{~nm}$. The weight of ingested carrot was estimated by interpolation on a standard curve obtained with the carotenoid values of methanolic extracts containing increasing weights of lyophilized carrot (Maestro et al., 2001). 
Peptides Mas-MIP II from M. sexta (Blackburn et al., 1995) and Grb-AST-B1 and Grb-AST-B3 from G. bimaculatus (Lorenz et al., 1995) were synthesized using standard Fmoc chemistry. The identity and purity (c. 90\%) of the peptides were assessed by amino-acid analysis, MALDI-TOF MS (matrix-assisted laser desorption ionization time-of-flight mass spectrometry) and HPLC.

\section{Results}

Before studying possible antifeeding effects of myoinhibitory peptides in $B$. germanica females, it was first assessed where these peptides could elicit antimyotropic effects in gut tissues. Therefore, we studied the dose-response effect of three peptides belonging to the myoinhibitory peptide family (Mas-MIP II, Grb-AST-B1 and GrbAST-B3) on B. germanica foregut and hindgut motility using a myotropic bioassay. Each of the three myoinhibitory peptides showed a strong myoinhibitory effect in terms of frequency and force on both tissues (Fig. 1). The three peptides gave an ID $_{50}$ value within the nanomolar range, and the maximum activity was between 40 and $60 \mathrm{mg}$ of decreasing force in the foregut, and between 6 and $10 \mathrm{mg}$ of decreasing force in the hindgut. The effect was very rapid, although the rate of contraction recovered partially within a few minutes of the treatment (Fig. 2).

The peptides Mas-MIP II, Grb-AST-B1 and Grb-AST-B3 were tested for effects on food intake by B. germanica using the carrot assay, and peptide doses from 5-50 $\mu \mathrm{g}$ per specimen were used. Grb-AST-B3 was the most active peptide, resulting in $c$. 60$80 \%$ inhibition of food intake at doses between 15 and $50 \mu \mathrm{g}$ (Fig. 3). Grb-AST-B1 resulted in c. $45 \%$ inhibition of food intake at the highest dose of $50 \mu \mathrm{g}$ (Fig. 3), whereas Mas-MIP II was inactive even at this dose (Fig. 3).

\section{Discussion}

It was postulated that myoinhibitory peptides could affect food intake in insects as a consequence of their effects on gut motility. Correspondingly, three galanin-related myoinhibitory peptides were tested as feeding modulators in adult females of the German cockroach, B. germanica. A standard feeding assay on adult females of $B$. germanica (Maestro et al., 2001) has shown that a number of peptides effectively 
inhibit food intake in this cockroach. These peptides include perisulfakinin (Maestro et al., 2001), YXFGL-NH $\mathrm{NH}_{2}$ allatostatins (Aguilar et al., 2003) and leucomyosuppressin (LMS) (Aguilar et al., 2004). Of these, LMS has the strongest antimyotropic activity on both foregut and hindgut, and it was suggested that this activity was responsible for its antifeedancy (Aguilar et al., 2004). Therefore, in the case of the myoinhibitory peptides studied here, both gut antimyotropic activity and antifeeding effect were assessed.

The three myoinhibitory peptides, Mas-MIP II, Grb-AST-B1 and Grb-AST-B3, induce a strong myoinhibitory action on the foregut and hindgut of $B$. germanica. When compared with other antimyotropic gut peptides studied in this species, the three myoinhibitory peptides are more active than YXFGL- $\mathrm{NH}_{2}$ allatostatins. Allatostatins are inactive on foregut, and show hindgut ID $_{50}$ values similar to those of myoinhibitory peptides (Aguilar et al., 2003 and Fig. 1). Conversely, myoinhibitory peptides are less active than LMS, with both foregut and hindgut ID $_{50}$ values around one order of magnitude higher than those of LMS (Aguilar et al., 2004 and Fig. 1). In contrast to the strong myoinhibitory effect of the three myoinhibitory peptides tested here in $B$. germanica, the myotropic peptide Pea-MIP cause only a moderate inhibition in foregut and hindgut muscle assays in the cockroach $P$. americana, with activity threshold concentrations as high as $5 \times 10^{-9} \mathrm{M}$ and $1 \times 10^{-7} \mathrm{M}$ for foregut and hindgut, respectively (Predel et al., 2001).

In spite of the similarity between myoinhibitory peptides and $\mathrm{N}$-terminal sequence of galanins, none of the three myoinhibitory peptides stimulate food intake. On the contrary, the peptides Grb-AST-B1 and B3 inhibit food intake in B. germanica, with Grb-AST-B3 the most active at c. $65 \%$ and $80 \%$ inhibition at doses of 15 and 50 $\mu \mathrm{g}$, respectively. However, Mas-MIP II is inactive at the maximum $50 \mu \mathrm{g}$ dose tested. Of the YXFGL-NH $\mathrm{N}_{2}$ allatostatins tested in the carrot-feeding bioassay (Aguilar et al., 2003), BLAST-2 (DRLYSFGL-NH ${ }_{2}$ ) show the highest activity, resulting in c. $60 \%$ inhibition of food intake at doses between 5 and $50 \mu \mathrm{g}$, whereas BLAST-1 (LYDFGL$\mathrm{NH}_{2}$ ) is the least active, inducing only c. $50 \%$ inhibition at a dose of $50 \mu \mathrm{g}$ (Aguilar et al., 2003). LMS (pQDVDHVFLRF- $\mathrm{NH}_{2}$ ) has a 50 and 75\% inhibitory effect on food intake at doses of 15 and $50 \mu \mathrm{g}$, respectively (Aguilar et al., 2004).

Thus, although all three myoinhibitory peptides inhibited gut motility in $B$. germanica in vitro to a similar extent, only Grb-AST-B3 and, to a lesser extent, GrbAST-B1 inhibited food intake. The different effects of the three tested myoinhibitory peptides on feeding could be due to the intrinsic influence of their structure on activity 
or to differences of stability in the haemocoel. However, from this study of the myoinhibitory peptides it is clear that myomodulatory gut activity in vitro and antifeeding effects do not always correlate.

\section{Acknowledgements}

Financial support from the Ministry of Science and Technology, Spain (project AGL2002-01169); and the Generalitat de Catalunya (2001 SGR 003245) is gratefully acknowledged.

\section{References}

Audsley, N. \& Weaver, R.J. (2003). Identification of neuropeptides from brains of larval Manduca sexta and Lacanobia oleracea using MALDI-TOF mass spectrometry and post-source decay. Peptides, 24, 1465-1474.

Aguilar, R., Maestro, J.L., Vilaplana, L. et al. (2004). Identification of leucomyosuppressin in the German cockroach, Blattella germanica, as an inhibitor of food intake. Regulatory Peptides, 119, 105-112

Aguilar, R., Maestro, J.L., Vilaplana, L. et al. (2003). Allatostatin gene expression in brain and midgut, and activity of synthetic allatostatins on feeding-related processes in the cockroach Blattella germanica. Regulatory Peptides, 115, 171-177.

Bersani, M., Johnsen, A.H., Hojrup, P. et al. Human galanin: primary structure and identification of two molecular forms. FEBS Letters, 283, 189-194.

Blackburn, M.B., Jaffe, H., Kochansky, J. \& Raina, A.K. (2001). Identification of four additional myoinhibitory peptides (MIPs) from the ventral nerve cord of Manduca sexta. Archives of Insect Biochemistry and Physiology, 48, 121-128. 
Blackburn, M.B., Wagner, R.M., Kochansky, J.P. et al. (1995). The identification of two myoinhibitory peptides, with sequence similarities to the galanins, isolated from the ventral nerve cord of Manduca sexta. Regulatory Peptides, 5, 213-219.

Crawley, J.N. (1999). The role of galanin in feeding behaviour. Neuropeptides, 33, 369375.

Davis, N.T., Blackburn, M.B., Golubeva, E.G. \& Hildebrand, J.G. (2003). Localization of myoinhibitory peptide immunoreactivity in Manduca sexta and Bombyx mori, with indications that the peptide has a role in molting and ecdysis. The Journal of Experimental Biology, 206, 1449-1460.

Ekblad, E., Håkanson, R., Sundler, F. \& Wahlestedt, C. (1985). Galanin: neuromodulatory and direct contractile effects on smooth muscle preparations. British Journal of Pharmacology, 6, 241-246.

Halford, J.C. \& Blundell, J.E. (2000). Pharmacology of appetite suppression. Progress in Drug Research, 54, 25-58.

Hua, Y.J., Tanaka, Y., Nakamura, K. et al. (1999). Identification of a prothoracicostatic peptide in the larval brain of the silkworm Bombyx mori. Journal of Biological Chemistry, 274, 31169-31173.

Lorenz, J.L., Lorenz, M.W. \& Hoffmann, K.H. (1997). Factors regulating juvenile hormone and ecdysteroid biosynthesis in Gryllus bimaculatus (Ensifera, Gryllidae). European Journal of Entomology, 94, 369-379.

Lorenz, M.W., Kellner, R. \& Hoffmann, K.H. (1995). A family of neuropeptides that inhibit juvenile hormone biosynthesis in the cricket, Gryllus bimaculatus. Journal of Biological Chemistry, 270, 21103-21108.

Lorenz, M.W., Kellner, R. \& Hoffmann, K. (1999). Allatostatins in Gryllus bimaculatus (Ensifera, Gryllidae): New structures and physiological properties. European Journal of Entomology, 96, 267-274. 
Lorenz, M.W., Kellner, R., Hoffmann, K.H. \& Gäde, G. (2000). Identification of multiple peptides homologous to cockroach and cricket allatostatins in the stick insect Carausius morosus. Insect Biochemistry and Molecular Biology, 30, 711-718.

Maestro, J.L., Aguilar, R., Pascual, N. et al. (2001). Screening of antifeedant activity in brain extracts led to the identification of sulfakinin as a satiety promoter in the German cockroach. Are arthropod sulfakinins homologous to vertebrate gastrinscholecystokinins? European Journal of Biochemistry, 268, 5824-5830.

McDonald, T.J., Krantis, A., Clarke, M. et al. (1992). Characterization of porcine gastric galanin. Peptides, 13, 589-593.

Osorio, S., Piulachs, M.D. \& Bellés, X. (1998). Feeding and activation of corpora allata in the cockroach Blattella germanica (L.) (Dictyoptera, Blattellidae). Journal of Insect Physiology. 44, 31-38.

Predel, R., Rapus, J. \& Eckert, M. (2001). Myoinhibitory neuropeptides in the American cockroach. Peptides, 22, 199-208.

Rattan, S. \& Tamura, W. (1998). Role of galanin in the gastrointestinal sphincters. Annals of the New York Academy of Sciences, 863, 143-155.

Schoofs, L., Holman, G.M., Hayes, T.K. \& Nachman, R.J. (1991). Isolation, identification and synthesis of locustamyoinhibiting peptide (LOM-MIP), a novel biologically active neuropeptide from Locusta migratoria. Regulatory Peptides, 36, 111-119.

Schoofs, L., Veelaert, D., Vanden Broeck, J. \& De Loof, A. (1996). Immunocytochemical distribution of Locusta myoinhibiting peptide (Lom-MIP) in the nervous system of Locusta migratoria. Regulatory Peptides, 63, 171-179. 
Vullings, H.G.B., Diederen, J.H.B., Veelaert, D. \& Van der Horst, D.J. (1999).

Multifactorial control of the release of hormones from the locust retrocerebral complex. Microscopy Research and Technique, 45, 142-153.

Wang, J., Meyering-Vos, M. \& Hoffmann, K.H. (2004). Cloning and tissue-specific localization of cricket-type allatostatins from Gryllus bimaculatus. Molecular and Cellular Endocrinology, 227, 41-51.

Williamson, M., Lenz, C., Winther, Å.M.E. et al. Molecular cloning, genomic organization, and expression of a B-type (cricket-type) allatostatin preprohormone from Drosophila melanogaster. Biochemical and Biophysical Research Communications, 282, 544-550.

Witek, G., Verhaert, P., Lorenz, M.W. \& Hoffmann, K.H. (1999). Immunolocalizaton of two types of allatostatins in the central nervous system of the cricket Gryllus bimaculatus (Ensifera: Gryllidae). European Journal of Entomology, 96, 279-285. 
Table 1. Comparison of the sequences of some myoinhibitory peptides with the Nterminal sequences of two typical vertebrate galanins. The coincident residues between the two groups of peptides have been hightlighted in bold.

\section{Galanins}

Human galanin 1

GWTLNSAGYLLGPHAVGNHRSFSDKNGLTS (1)

Porcine galanin

GWTLNSAGYLLGPHAIDNHRSFHDKYGLA-NH ${ }_{2}$ (2)

\section{Myoinhibitory peptides}

Mas-MIP I

AWQDLNSAW-NH 2 (3)

Mas-MIP II

GWQDLNSAW-NH $\mathrm{N}_{2}$ (3)

Mas-MIP IV

GWNDMSSAW-NH $\mathrm{N}_{2}$ (4)

Mas-MIP V

GWQDMSSAW-NH 2 (4)

Grb-AST-B1

GWQDLNGGW-NH 2 (5)

Grb-AST-B2

GWRDLNGGW-NH $\mathrm{N}_{2}$ (5)

Grb-AST-B3

AWRDLSGGW-NH $\mathrm{N}_{2}(5)$

Cam-AST-B3

GWQDLQSGW-NH ${ }_{2}$ (6)

Cam-AST-B6

AWQDLGSAW-NH $\mathrm{NH}_{2}$ (6)

Pea-MIP

GWQDLQGGW-NH 2 (7)

(1) Bersani et al., 1991; (2) McDonald et al., 1992; (3) Blackburn et al., 1995; (4) Blackburn et al., 2001;

(5) Lorenz et al., 1995; (6) Lorenz et al., 2000; (7) Predel et al., 2001. 


\section{FIGURE LEGENDS}

Fig. 1. Inhibitory effect of the myoinhibitory peptides Mas-MIP II (GWQDLNSAW$\mathrm{NH}_{2}$ ), Grb-AST-B1 (GWQDLNGGW-NH ${ }_{2}$ ) and Grb-AST-B3 (AWRDLSGGW-NH on foregut (top) and hindgut (bottom) motility in B. germanica females. Results (mean $\pm \mathrm{SEM} ; \mathrm{n}=5-7)$ are expressed as the difference of the mean of the force produced by the tissue during one minute after and before the treatment. The $\mathrm{ID}_{50}$ for each tissue is also shown. Empty squares indicate values for water control experiments.

Fig. 2. Representative response of foregut (left) and hindgut (right) organ bath preparations to the myoinhibitory peptide Mas-MIP-II. Arrows indicate application of the peptide and the concentration used.

Fig. 3. Effect of the myoinhibitory peptides Mas-MIP II (GWQDLNSAW-NH ${ }_{2}$ ), GrbAST-B1 (GWQDLNGGW-NH ${ }_{2}$ ) and Grb-AST-B3 (AWRDLSGGW-NH ${ }_{2}$ ) on food intake in B. germanica females. Results are expressed as mean \pm SEM. The number of replicates is indicated at the top of each bar. Asterisks indicate significant differences (Student's $t$ test) with respect to the corresponding control ( $* P<0.05$; ** $P<0.01$; *** $P<0.001)$. 

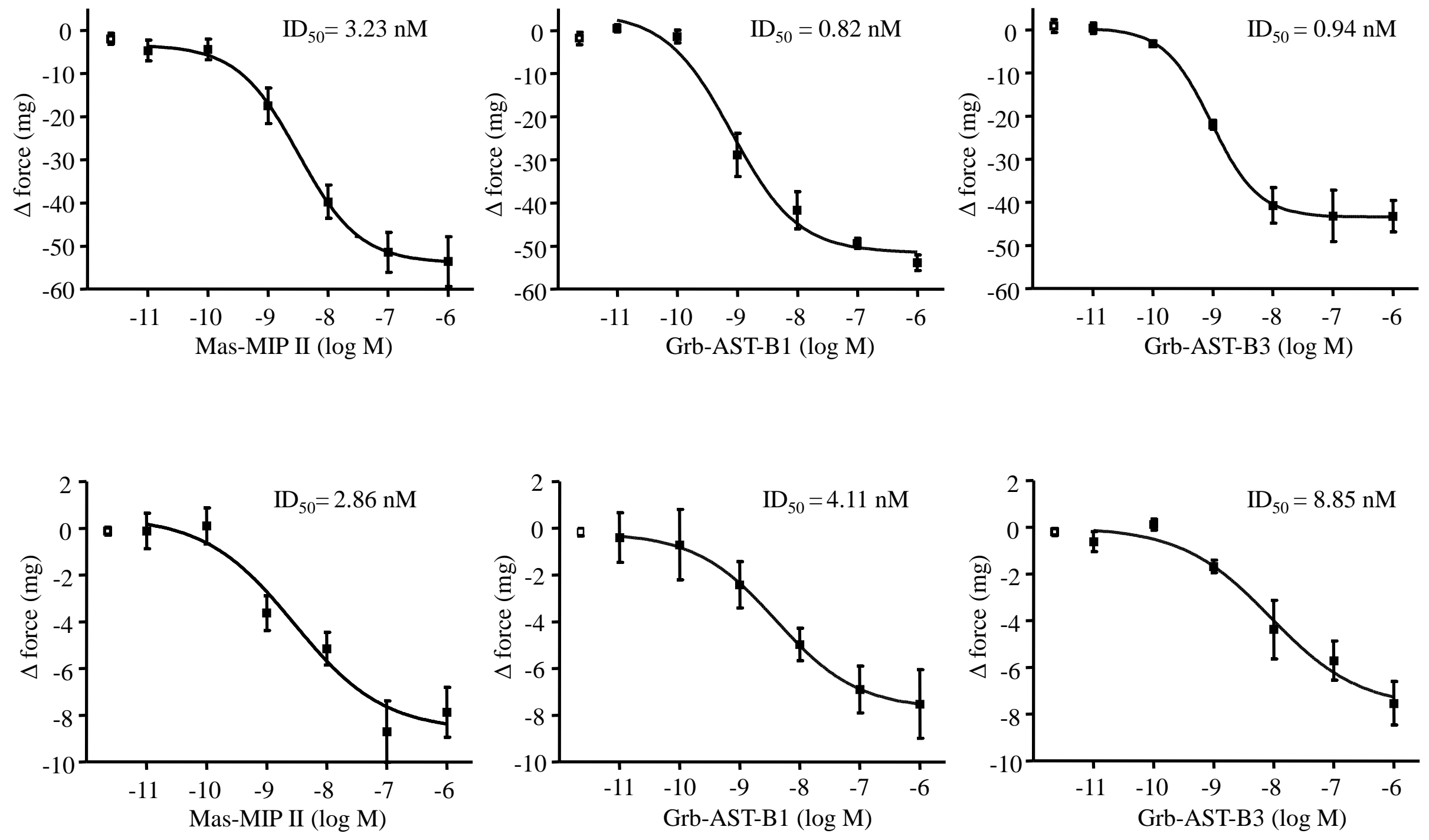

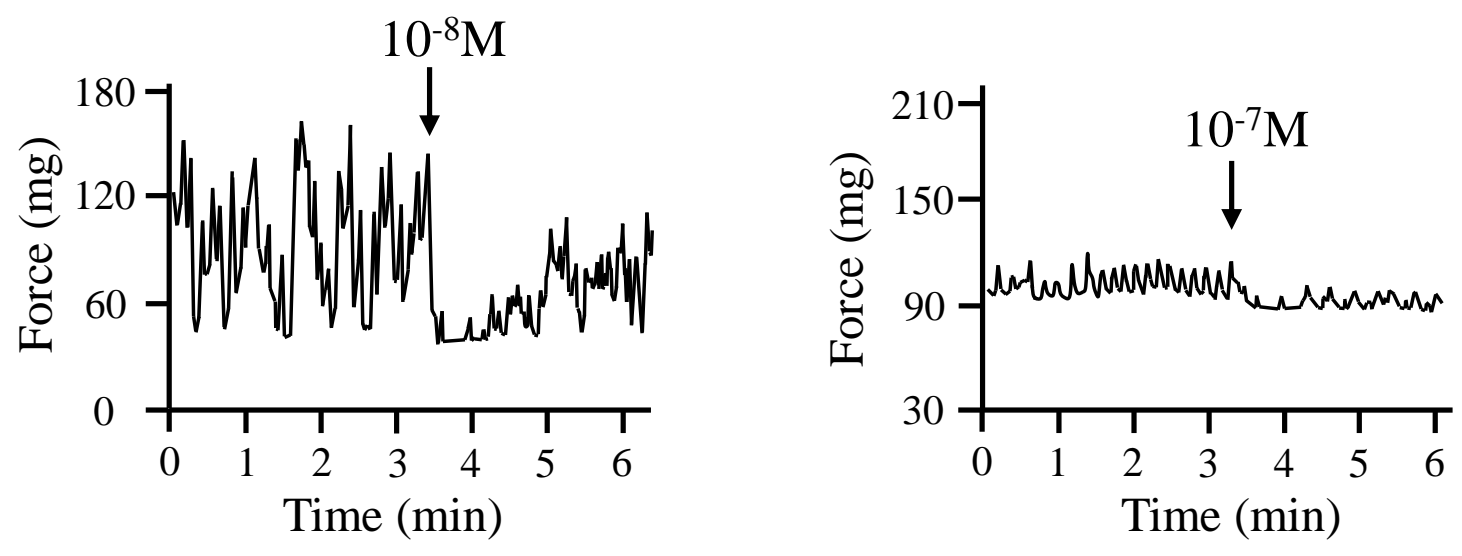


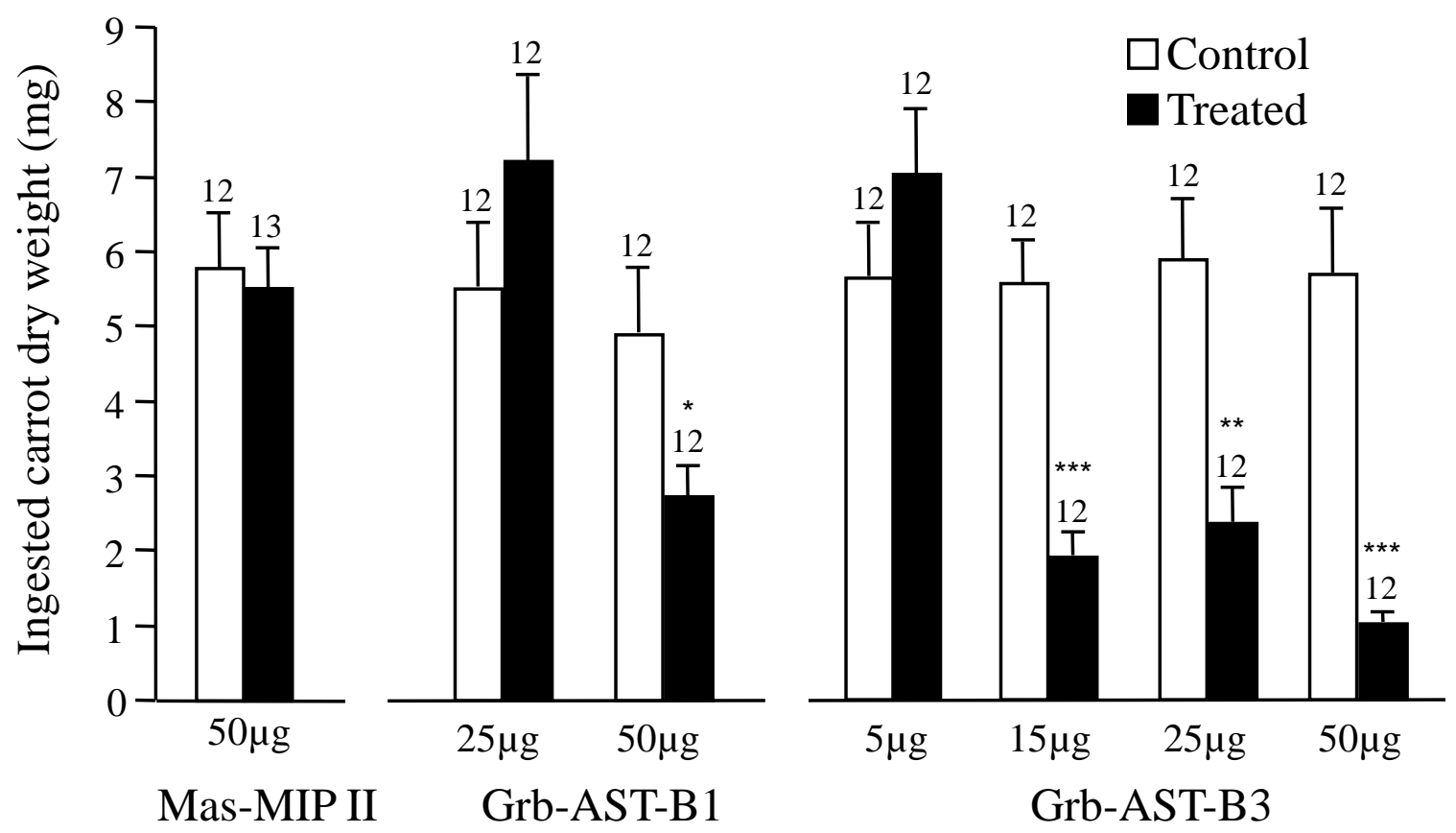

